\title{
DETERMINATION OF TOTAL PHENOL, FLAVONOID, ANTIOXIDANT ACTIVITY OF OIL PALM LEAVES EXTRACTS AND THEIR APPLICATION IN TRANSPARENT SOAP
}

\author{
NORASHIKIN AHMAD*; ZAFARIZAL ALDRIN AZIZUL HASAN*; HALIMAH MUHAMAD*; \\ SITI HAJAR BILAL*; NOR ZULIANA YUSOF* and ZAINAB IDRIS*
}

\begin{abstract}
Oil palm leaves (OPAL) extract is gaining considerable interest as it is derived from a natural source and provides many functions such as anti-microbial effect towards bacteria, good ultraviolet (UV) protection and possesses the ability to combat several skin diseases due to its antioxidant properties. In this study, the phenolic compounds from OPAL extracted via four different extraction procedures i.e. extraction with ethanol (OPAL M1), extraction with hexane and followed by ethanol (OPAL M2), extraction with hexane and with ethanolic hydrochloric acid (OPAL M3) and aqueous extraction (OPAL M4) were studied. Total phenolic content (TPC) and total flavonoid content (TFC) of the OPAL extracts were determined and their antioxidant activity compared with butylated hydroxytoluene (BHT). The results indicated that OPAL M1 and OPAL M2 had higher TPC and TFC than OPAL M3 and OPAL M4. All OPAL extracts showed antioxidant activities similar to BHT but required a higher concentration. The transparency and brightness of the transparent soaps formulated with OPAL extract were not affected at $0.1 \%$ concentration. Thus, OPAL extracts have the potential to be used as natural antioxidant and colourant in transparent soaps.
\end{abstract}

Keywords: OPAL extracts, total phenolic content, total flavonoid content, DPPH, transparent soap.

Date received: 12 July 2017; Sent for revision: 13 July 2017; Received final form: 29 September 2017; Accepted: 10 January 2018.

\section{INTRODUCTION}

Palm leaves, a by-product of the palm oil industry, are a potential source of beneficial compounds suitable for food and non-food applications. The palm leaves have been used as ruminant feed for decades without any report of toxicity. However, the high content of insoluble fibre has been the main problem why palm leaves could not be used directly in our food. The leaves have been used indirectly as woven bags for boiling rice and polyphenols

Malaysian Palm Oil Board

6 Persiaran Institusi, Bandar Baru Bangi,

43000 Kajang, Selangor, Malaysia.

E-mail: shikin@mpob.gov.my absorbed into the boiled rice do give a desirable flavour and aroma (Suhaila, 2014).

Numerous researches have been carried out on the extraction and potential uses of natural antioxidants derived from plants. There are three major groups in plants which contribute to the antioxidant activity i.e. carotenoids, vitamins and phenolics. Carotenoids and vitamin $\mathrm{E}$ are known as lipophilic antioxidants while vitamins $C$ and phenolic compounds are known as hydrophilic antioxidants (Halliwell, 1996). There are various established methods for the extraction of phenolic compounds from plant materials. The methods are varied in the solvents and conditions used.

Phenolic compounds such as flavonoids, tannins, coumarins, alkaloids, saponins, terpenoids, 
steroids and carbohydrates, with flavonoids being the main constituents, were found in oil palm leaves (OPAL) alcoholic extract ( $\mathrm{Ng}$ et al., 2013). Jaffri et al. (2011) reported that the main flavonoids present in OPAL were flavanols i.e. epigallocatechin $(0.8 \mathrm{mg}$ $\left.\mathrm{g}^{-1}\right)$, catechin $\left(3.0 \mathrm{mg} \mathrm{g}^{-1}\right)$, epicatechin $\left(0.1 \mathrm{mg} \mathrm{g}^{-1}\right)$, epigallocatechin gallate $\left(2.8 \mathrm{mg} \mathrm{g}^{-1}\right)$, epicatechin gallate $\left(0.5 \mathrm{mg} \mathrm{g}^{-1}\right)$ and their glucosides.

Phenolic compounds play an important role as antioxidants ( $\mathrm{Ng}$ and Choo, 2010; Aksoy et al., 2013). Moreover, the beneficial effect of phenolic compounds from palm oil leaves showed antimicrobial activities towards Gram positive bacteria and good UVA and UVB protection in topical application (Yusof et al., 2016). Besides, phenolic compounds also contribute towards colour protecting leaf cells from photooxidative damage in many plants (Feild et al., 2001). Natural colourant from plant can be grouped into three classes; tetrapyrrols (such as chlorophyll), tetraterpenoids (such as carotenoids) and flavonoids (such as anthocyanins) (Mortensen, 2006). Flavonoids are a family of phenolic compounds with several sub-classes such as anthocyanidins, flavanones, flavanols, flavones, flavonols and isoflavones. These groups are categorised as low molecular weight compounds and consist of 15 carbon atoms, arranged in a $\mathrm{C}_{6}-\mathrm{C}_{3}-\mathrm{C}_{6}$ configuration. Several studies have emphasised that flavonoids in plant sources can perform free-radical scavenging activity and provide protection against oxidative stress (Alothman et al., 2009; Enujiugha et al., 2012).

Transparent soap is basically made from a blend of soap (neutralised fatty acids) and solvent such as alcohol, glycerine and sugar. All ingredients used to make transparent soap must be of high quality, clear and do not form any solid soap crystals when cooled (Instone and Bottarelli, 1991). The usage of transparent soap is similar to opaque soap. However, the transparent soap is relatively more attractive and better moisturising than opaque soap. In order to add value to transparent soap, plant extracts have been incorporated to provide natural colour and antioxidant. The most commonly used synthetic antioxidants in cosmetic and personal care products are butylhydroxyanizole (BHA), butyl hydroxytolune (BHT), propyl gallate (PG) and tert butylhydroquinone (TBHQ). These compounds have been under scrutiny due to their potential injurious effect on health such as having carcinogenic effects, allergic contact dermatitis and other adverse effects (Sun and Fukura 1997; Yamaki et al., 2007). Therefore, there is a growing interest in natural and safer antioxidants.

The aim of this study was to analyse the phenolic and flavonoid contents of OPAL with different methods of extraction. In addition, the antioxidant properties of OPAL extracts were compared with BHT. Then, the effects of OPAL extracts and BHT in transparent soaps toward transparency and colour intensity were also evaluated.

\section{MATERIALS AND METHODS}

\section{Chemical and Apparatus}

OPAL powder was obtained from Fyllo (M) Sdn Bhd, Malaysia. Hexane was purchased from Fisher Scientific, USA. Ethanol was obtained from John Kollin Corporation, United Kingdom and methanol was purchased from Fisher Scientific, United Kingdom. All solvents used were of analytical grade unless otherwise specified. Hydrochloric acid $(\mathrm{HCl})$ with $37 \%$ purity and sodium hydroxide $(\mathrm{NaOH})$ with $99 \%$ purity were obtained from Merck, UK and Merck, Germany. Sodium carbonate anhydrous $\left(\mathrm{Na}_{2} \mathrm{CO}_{3}\right)$ with $99.5 \%$ purity was supplied by $\mathrm{R} \& \mathrm{M}$ Marketing, UK. Aluminum chloride $\left(\mathrm{AlCl}_{3} \cdot 6 \mathrm{H}_{2} \mathrm{O}\right)$ and BHT with $99 \%$ purity was obtained from SigmaAldrich, Germany. Gallic acid, Folin-Ciocalteau reagent i.e. 2,2-Diphenyl-1-picrylhydrazyl (DPPH) radical and sodium nitrite $\left(\mathrm{NaNO}_{2}\right)$ with $\geq 99 \%$ purity were supplied from Sigma-Aldrich, USA. Trolox (6-hydroxy-2,5,7,8-tetramethylchromane-2carboxylic acid), 97\% was purchased from Acros, Organics, USA. Meanwhile (-)-epicathecin (EC) with $\geq 98 \%$ purity was purchased from Nacalai Tesque Inc, Japan. Fatty acids were purchased from Emery Oleochemicals (M) Sdn Bhd, Malaysia. Glycerin was purchased from Croda, Seraya Avenue, Singapore. Ethylenediaminetetraacetic acid disodium salt (EDTA) was purchased from Ajax Finechem Pty Ltd, Australia. Sodium laureth sulphate (SLES) was purchased from BASF, Germany and lactic acid was obtained from Purac Biochem, United Kingdom. Reverse osmosis water was used. Filter paper no. 4 was purchased from Whatman International Ltd (Maidstone, United Kingdom). Digital rotary evaporator IKA RV 10 (IKA, Germany) was used to remove solvent. Spectrophotometric determinations were performed on a UV-Visible Spectrophotometer, model UV-1800 from Shimadzu Corporation, Japan. Chroma Meter CR300, Konica Minolta, Inc., Japan was used to measure colour luminosity of transparent soap.

\section{Preparation of OPAL Extracts}

Four different methods were used to prepare the OPAL extract.

First extraction method (OPAL M1). The $20 \mathrm{~g}$ OPAL powder was mixed in $200 \mathrm{ml}$ ethanol. The mixture was stirred on a magnetic stirrer under a reflux condenser at $78^{\circ} \mathrm{C}$ for $2 \mathrm{hr}$. The extract obtained was then filtered through a filter paper after the mixture was cooled to room temperature (RT). The solvent 
was removed by a rotary evaporator. The crude extract obtained was kept in a dark glass bottle.

Second extraction method (OPAL M2). The $20 \mathrm{~g}$ OPAL powder was soaked in $200 \mathrm{ml}$ hexane. The mixture was stirred at RT overnight. The solvent was then filtered off through a filter paper to remove fatty materials. The OPAL powder that was free from fatty materials was subjected to ethanol extraction. The crude extract was kept in a dark glass bottle.

Third extraction method (OPAL M3). The amount of OPAL powder and solvent was similar to the OPAL M2 method. However, $5 \mathrm{ml}$ of $6 \mathrm{M} \mathrm{HCl}$ was introduced in the extraction of phenolic. The crude extract obtained was kept in a dark glass bottle.

Fourth extraction method (OPAL M4). The $20 \mathrm{~g}$ OPAL powder was mixed with $200 \mathrm{ml}$ deionised water. The mixture was heated at $100^{\circ} \mathrm{C}$ under refluxed for $2 \mathrm{hr}$. The extract was then cooled to RT and filtered through filter paper. The extract was concentrated under reduced pressure using a rotary evaporator. The crude extract obtained was kept in a dark glass bottle.

\section{Determination of Total Phenolics Content}

Total phenolics of the OPAL extracts and the standard gallic acid were determined using FolinCiocalteau method (Singleton and Rossi, 1965). The gallic acid stock solution (1 $\mathrm{mg} \mathrm{ml}^{-1}$ concentration) was prepared by dissolving $25 \mathrm{mg}$ gallic acid powder in $25 \mathrm{ml}$ methanol. Then, gallic acid working solution with six concentrations were prepared $(0.5,0.25,0.125,0.0625,0.03125$ and $0.015625 \mathrm{mg} \mathrm{ml}^{-1}$ ). About $0.1 \mathrm{ml}$ gallic acid was added to $0.5 \mathrm{ml}$ Folin-Ciocalteau reagent (10\% solution), followed by $7 \mathrm{ml}$ deionised water. The mixture was left in the dark at RT for $10 \mathrm{~min}$. Then, $1.5 \mathrm{ml} \mathrm{Na} \mathrm{CO}_{3}$ (7.5\% solution) was added and the mixture was left at RT for another $2 \mathrm{hr}$. UV absorbance was measured at $765 \mathrm{~nm}$ using UVVisible Spectrophotometer. Methanol was used as a blank. Gallic acid at various concentrations was used for preparing a standard calibration curve. For OPAL extracts, samples were prepared by dissolving $10 \mathrm{mg}$ of plant extract in $10 \mathrm{ml}$ methanol (1 $\mathrm{mg} \mathrm{ml}^{-1}$ concentration). Then, $0.1 \mathrm{ml}$ of the OPAL solution was used for determination of total phenolic in plant extract. According to Abdelhady et al. (2011), the total phenolics content was calculated in mg gallic acid equivalent (GAE) $\mathrm{g}^{-1}$ of extract by the following equation:

$$
\mathrm{TPC}=\mathrm{C} \times \mathrm{V} / \mathrm{M}
$$

where TPC is the total phenolics content in mg GAE g-1 of the extract, $C$ is the concentration of gallic acid established from the calibration curve in $\mathrm{mg} \mathrm{ml}^{-1}, V$ is the volume of the extract solution in $\mathrm{ml}$ and $M$ is the weight of the extract in $\mathrm{g}$.

\section{Determination of Flavonoid Content}

Total flavonoid content (TFC) was determined using UV-Visible Spectrophotometer. Briefly, $0.5 \mathrm{ml}$ extract was mixed with $2.5 \mathrm{ml}$ of distilled water in test tube, followed by adding $0.15 \mathrm{ml}$ of a $5 \% \mathrm{NaNO}_{2}$ solution. The mixture was left as RT for $6 \mathrm{~min}$. Then, $0.3 \mathrm{ml}$ of a $10 \% \mathrm{AlCl}_{3} \cdot 6 \mathrm{H}_{2} \mathrm{O}$ solution was added and allowed to stand for another $5 \mathrm{~min}$ before adding $1 \mathrm{ml}$ of $1 \mathrm{M} \mathrm{NaOH}$. The mixture was made up to $5 \mathrm{ml}$ with distilled water and mixed well. The orange solution was measured immediately against methanol at $510 \mathrm{~nm}$. The results were recorded as micrograms of EC equivalent ( $\mathrm{mg}$ of EC per $\mathrm{g}$ sample) using calibration curve of EC. The TFC was calculated using similar equation for TPC. Linearity range of the calibration curve was prepared from 0.015625 to $0.5 \mathrm{mg} \mathrm{ml}^{-1}$.

\section{Determination of DPPH Radical Scavenging Activity}

DPPH radical scavenging activity was carried out as described by Yen and Duh (1994) and Thaipong et al. (2006) with slight modifications. For preparing DPPH stock, $10 \mathrm{ml}$ of the stock solution was diluted with $45 \mathrm{ml}$ methanol for the working solution. Control sample containing 0.15 $\mathrm{ml}$ methanol and $2.85 \mathrm{ml}$ DPPH was measured at $515 \mathrm{~nm}$. According to Neo et al. (2008), the control sample should provide absorbance reading of $1.10 \pm 0.03$ units at $515 \mathrm{~nm}$. In this study, $2.85 \mathrm{ml}$ DPPH working solution was added to the $0.15 \mathrm{ml}$ Trolox, OPAL extract solutions and BHT solutions, respectively. Each mixture was kept in the dark at RT for $1 \mathrm{hr}$. The colour changes from deep violet to light yellow were measured spectrophotometrically at $515 \mathrm{~nm}$. Trolox at various concentrations (ranging from 0.015625 to $0.25 \mathrm{mg} \mathrm{ml}^{-1}$ ) in methanol was used to prepare a standard curve. The concentration of OPAL and BHT samples were prepared ranging from 0.0625 to $2.00 \mathrm{mg} \mathrm{ml}^{-1}$ and 0.03125 to $0.25 \mathrm{mg}$ $\mathrm{ml}^{-1}$. The percentage of inhibition of the DPPH was calculated as follows:

DPPH inhibition, $\%=\left[\frac{\mathrm{A}(\text { control })-\mathrm{A}(\text { standard } / \text { sample })}{\mathrm{A}(\text { control })}\right] \times 100$

where $\mathrm{A}$ (control) is the absorbance of the methanol with DPPH and A(sample) is the absorbance of the standard or sample with DPPH. Inhibition concentration at 50\% $\left(\mathrm{IC}_{50}\right)$ obtained from linear regression graph was used to determine the concentration of the sample required to inhibit 50\% of the DPPH-free radical. 


\section{Preparation of Transparent Soap Base}

The $25 \mathrm{~g}$ of fatty acids was melted at $75^{\circ} \mathrm{C}-80^{\circ} \mathrm{C}$ and $4 \mathrm{~g}$ of sodium hydroxide was dissolved in 10 $\mathrm{ml}$ of water. The $\mathrm{NaOH}$ solution was added into the melted fatty acids. The mixture was stirred until solid soap was formed. In another vessel, polyols such as glycerin, EDTA, water, SLES surfactant were stirred and heated to $75^{\circ} \mathrm{C}-85^{\circ} \mathrm{C}$ until all ingredients were fully dissolved. Then, this mixture was added into the solid soap. The mixture was continuously stirred and heated until the solid soap was completely dissolved. The $\mathrm{pH}$ of the mixture was adjusted with lactic acid to $\mathrm{pH}$ 9-10. Finally, the mixture was poured into mould and cool it down at RT until the soap harden. The transparent soap base was wrapped with plastic for further study.

\section{Preparation of Transparent Soap with OPAL extracts and BHT}

Transparent soap base was melted at $75^{\circ} \mathrm{C}-80^{\circ} \mathrm{C}$ in water bath. Then, the temperature of the soap was reduced to $60^{\circ} \mathrm{C}-70^{\circ} \mathrm{C}$ and OPAL extract or BHT was added into the soap at $0.1 \%$ and $0.5 \%$. The mixture was stirred until it becomes homogenous and finally poured into a mould. The soap was covered with a plastic after $1 \mathrm{hr}$ or the soap had completely hardened and stored at RT for analysis.

\section{Transparency}

The soaps without and with active were poured into plastic mould with 0.25 inch or $6.4 \mathrm{~mm}$ soap thickness and transparency was observed visually at RT.

\section{Determination of Transparent Soap Colour Intensity with OPAL Extracts and BHT}

Colour measurements of the palm-based transparent soap without extract, with OPAL extracts and BHT were carried out using Chroma Meter according to the Commission Internationale de l'Eclairage (CIE) $L^{*} a^{*} b^{*}$ colour scale. The Chroma Meter measures the sample surface of 8 $\mathrm{mm}$ in diameter at wavelengths $(400-700 \mathrm{~nm})$ of transmitted light, standard observer $\left(0^{\circ}\right)$ and under illuminant D65. This system consists of the following parameters: $\mathrm{L}^{*}$, which refers to luminosity (white to black); $+\mathrm{a}^{*}$ and $-\mathrm{a}^{*}$, which refers to the red and green colour axis while $+b^{*}$ and $-b^{*}$, which refers to yellow and blue axis. The spectrophotometer was calibrated using white calibration plate. The soap was placed on a white paper and measurement was taken from top of the soap. The $\mathrm{L}^{*}$ readings of the sample were recorded in order to determine the colour luminosity of transparent soap with OPAL extracts and BHT. A total of 10 readings were taken and a mean value was obtained for the sample.

\section{Statistical Analysis}

Analysis of variance (ANOVA) single factor and Student t-Test tests were used to compare any significant differences between samples. The values were expressed as means and standard deviation. The differences were considered significant if probability, $\mathrm{p}<0.05$. All analysis was carried out in triplicates.

\section{RESULTS AND DISCUSSION}

\section{Extract Yields}

The efficiencies of different extraction methods, OPAL M1, M2, M3 and M4 were based on the yield of the respective extracts. OPAL M3 extraction method gave the highest yield of $51 \%$ followed by OPAL M4 (27\%), OPAL M2 (16\%) and the lowest was OPAL M1 $(15 \%)$. It was found that by using hexane and $\mathrm{HCl}$, it managed to remove waxy materials, destructed cell membranes, thereby rendering compounds more accessible to the extraction thereby increasing the yield. Solvent polarity also plays an important role in extraction. The results showed that the extraction yield increased with increasing polarity of the solvent used in the extraction. These results are in agreement with the extraction yield of Limnophila aromatica plant where the yield for water extraction was higher than ethanol (Do et al., 2014). The appearances of OPAL M1, M2, M3 and M4 were dark green and waxy, dark green and not waxy, dark reddish-purple and dark olive green, respectively. In addition, by removing the waxy materials, the OPAL extract was easy to dissolve and incorporate in the product formulation.

\section{Total Phenolic Content}

Phenolic compounds and polyphenols are naturally present in plants as antioxidants. Waterhouse (2002) reported that the Folin-Ciocalteu method provides accurate measurements of TPC where the yellow colour of Folin reagent changed to blue indicating that the Folin reagent reacted equally with various groups of phenolic compounds. The standard calibration curve for gallic acid at concentrations of $0.015625,0.03125,0.0625,0.125$, 0.25 and $0.5 \mathrm{mg} \mathrm{ml}^{-1}$ is shown in Figure 1. The results for TPC of OPAL extracts were calculated using the standard calibration curve of gallic acid with a correlation coefficient $\left(\mathrm{R}^{2}\right)$ of 0.9963 . The TPC of OPAL extracts are determined by the Folin-Ciocalteau assay and calculated as $\mathrm{mg} \mathrm{g}^{-1}$ GAE. Results are the average of triplicates \pm standard deviation (SD) and presented in Figure 2. It was observed that different 
extraction methods exhibited different TPC. ANOVA showed strong significant difference between all extraction methods. Further analysis was carried out to investigate the differences between the means using Student t-Test analysis. The results showed that there were significant differences between all extraction methods with $\mathrm{p}<0.05$. Analysis of the phenolic content in all extracts using the FolinCiocalteu method revealed that OPAL M1 contained the highest phenolic content at $1.160 \pm 0.001 \mathrm{mg} \mathrm{g}^{-1}$ followed by OPAL M2 (0.982 $\left.\pm 0.001 \mathrm{mg} \mathrm{g}^{-1}\right)$, OPAL M4 $\left(0.440 \pm 0.006 \mathrm{mg} \mathrm{g}^{-1}\right)$ and OPAL M3 $(0.304 \pm 0.044$ $\left.\mathrm{mg} \mathrm{g}^{-1}\right)$. In the second extraction method, hexane was used to eliminate the oily and non-polar residue of the OPAL before proceeding with the ethanol extraction. However, this step resulted in a decrease of the TPC. Thus, OPAL M2 showed lower TPC than OPAL M1. The result is in agreement with a study carried out by Tasioula-Margari and Tsabolatidou (2015) in which by reducing the number of washing with hexane on virgin olive oil extract managed to further increase in recoveries of TPC. Shahidi and Yeo (2016) ascribed that $\mathrm{HCl}$ has been widely used in the extraction of insoluble-bound phenolics. Acid hydrolysis involved simple steps for the extraction and can be used directly for further experimentation after neutralisation and filtration, unlike alkaline extraction which requires an additional extraction procedure using diethyl ether. However, phenolic compounds are unstable at low $\mathrm{pH}$, thus they can be degraded during the extraction process. Therefore, this is a clear evident that OPAL M3 extracted in the presence of $\mathrm{HCl}$ showed the lowest TPC. Previous studies reported that TPC of dried OPAL extract in the presence of $\mathrm{HCl}$ was 5.1-10.2 $\mathrm{mg} \mathrm{GAE} \mathrm{g}^{-1}$ extract ( $\mathrm{Ng}$ and Choo, 2010), while TPC of OPAL extract without $\mathrm{HCl}$ was $9.84 \pm 0.06 \mathrm{mg} \mathrm{GAE} \mathrm{g}^{-1}$ extract (Yusof et al., 2016) and $24.3 \mathrm{mg} \mathrm{GAE} \mathrm{per} \mathrm{g-1}$ extract (Runnie et al., 2003).

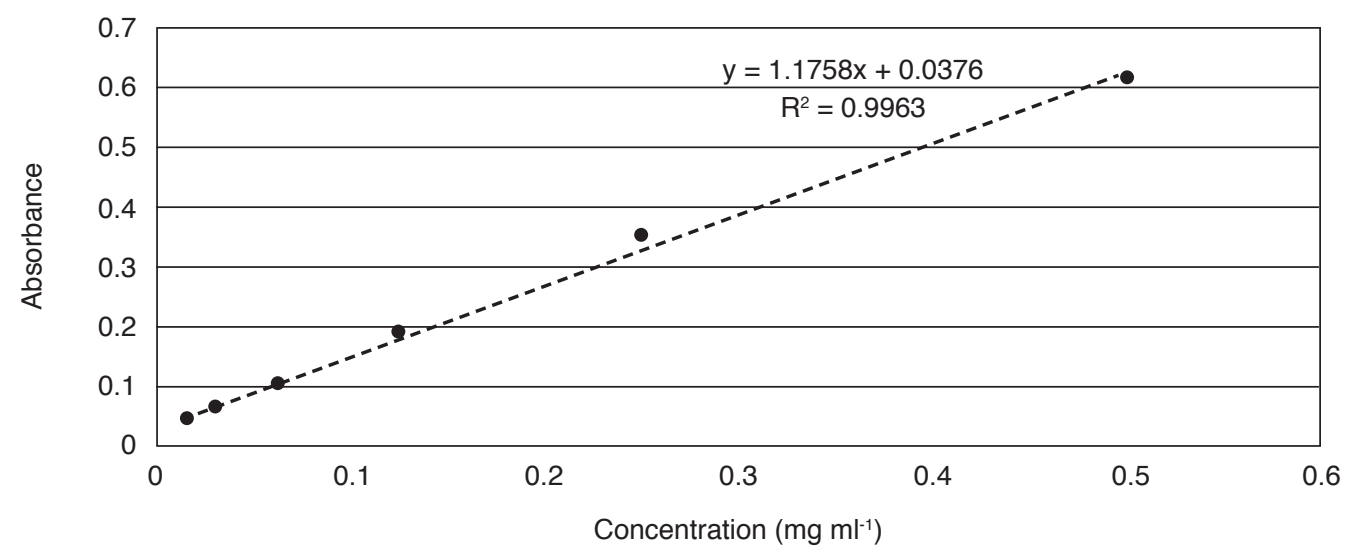

Figure 1. Standard calibration curve of gallic acid.

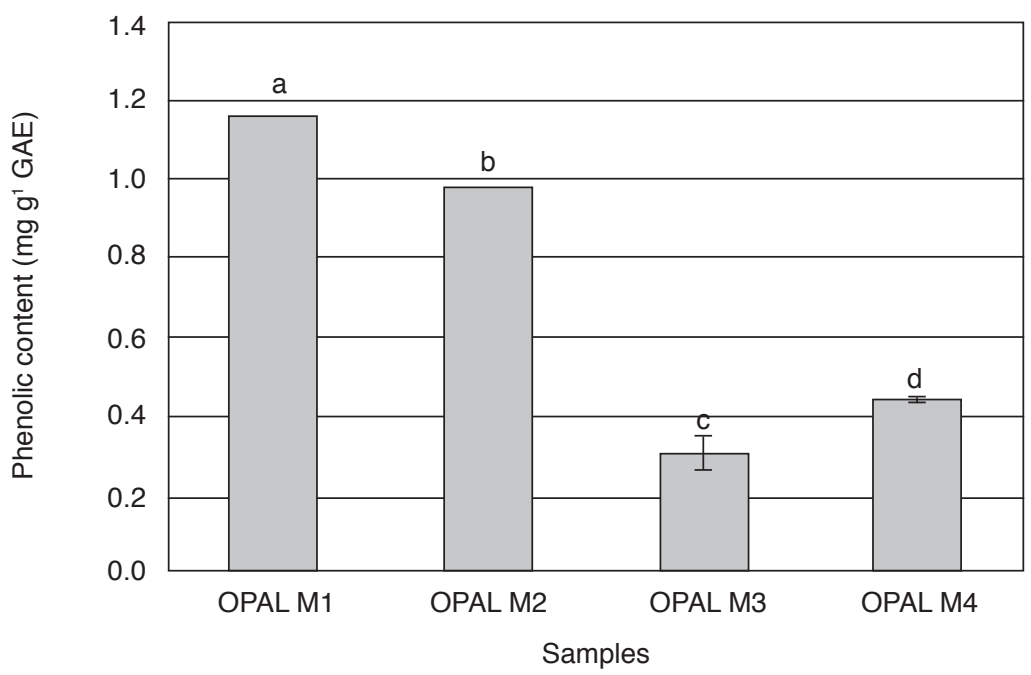

Figure 2. Total phenolics content of oil palm leaves (OPAL) extract from various methods of extraction. Values in the same column followed by different letters indicate significant differences $(p<0.05)$. 


\section{Total Flavonoid Content}

In this study, the flavonoids content was calculated in terms of EC equivalent (mg EC per $\mathrm{g}$ extract). The EC was used as standard at concentrations ranging from 0.015625 to $0.5 \mathrm{mg} \mathrm{ml}^{-1}$ in methanol and the graph is illustrated in Figure 3. The graph showed regression equation of calibration curve ( $\left.y=2.9522 x-0.0066, R^{2}=0.9995\right)$. In order to estimate the amount of flavonoids in OPAL extracts, TFC of the extracts was analysed and results are the average of triplicates \pm SD (Figure 4). OPAL extracts from different extraction methods differed significantly $(\mathrm{p}<0.05)$ in their TFC. The order of TFC in the different extracts was as follows: OPAL M1 $\left(1.16 \pm 0.001 \mathrm{mg} \mathrm{g}^{-1}\right)$, OPAL M2 $\left(0.55 \pm 0.002 \mathrm{mg} \mathrm{g}^{-1}\right)$, OPAL M4 (0.33 $\left.\pm 0.001 \mathrm{mg} \mathrm{g}^{-1}\right)$ and OPAL M3 (0.30 $\left.\pm 0.002 \mathrm{mg} \mathrm{g}^{-1}\right)$. OPAL M1 extraction method was more effective for extraction of flavonoid compared to other methods and ethanol was found to be the suitable solvent to extract the flavonoids compared to water. OPAL M3 showed the lowest flavonoid content among OPAL extractions. Treatment of $\mathrm{HCl}$ in OPAL M3 method has resulted in a drastic reduction of the extract's $\mathrm{pH}$ to $\mathrm{pH} 1$ while other OPAL extracts gave $\mathrm{pH}$ value of $\mathrm{pH}$ 5. Many articles reported that acid hydrolysis was required for isolation of phenolics from plants and important for the stability of the phenolics in the extract (Khoddami et al., 2013; Jaffri et al., 2011; Neo et al., 2008; Ng and Choo, 2010). However, DavidovPardo et al. (2011) reported that $\mathrm{pH} 4-5$ was the ideal condition for catechins, their isomers and polymers instead of more alkaline or acidic condition. Thus, the lowest TFC for OPAL M3 was due to the extreme acidic condition and it was in agreement with the statement.

\section{DPPH Scavenging Effect}

The OPAL extracts and BHT as a benchmark were assessed for their capacity to scavenge DPPH along with Trolox as a positive control. Figure 5 shows standard calibration curve of Trolox at

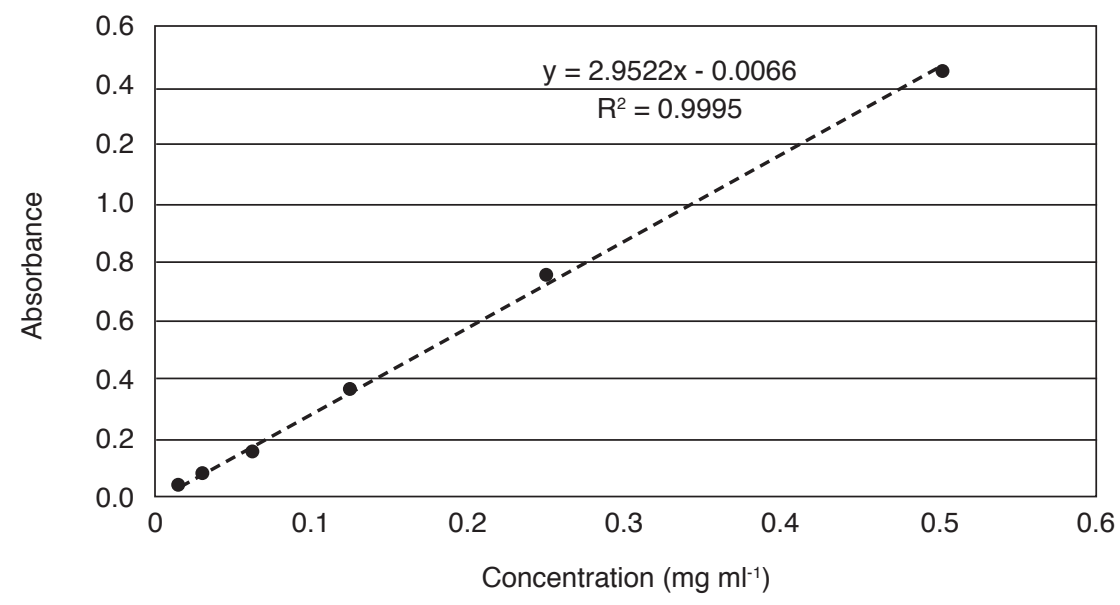

Figure 3. Standard calibration curve of epicathecin (EC).

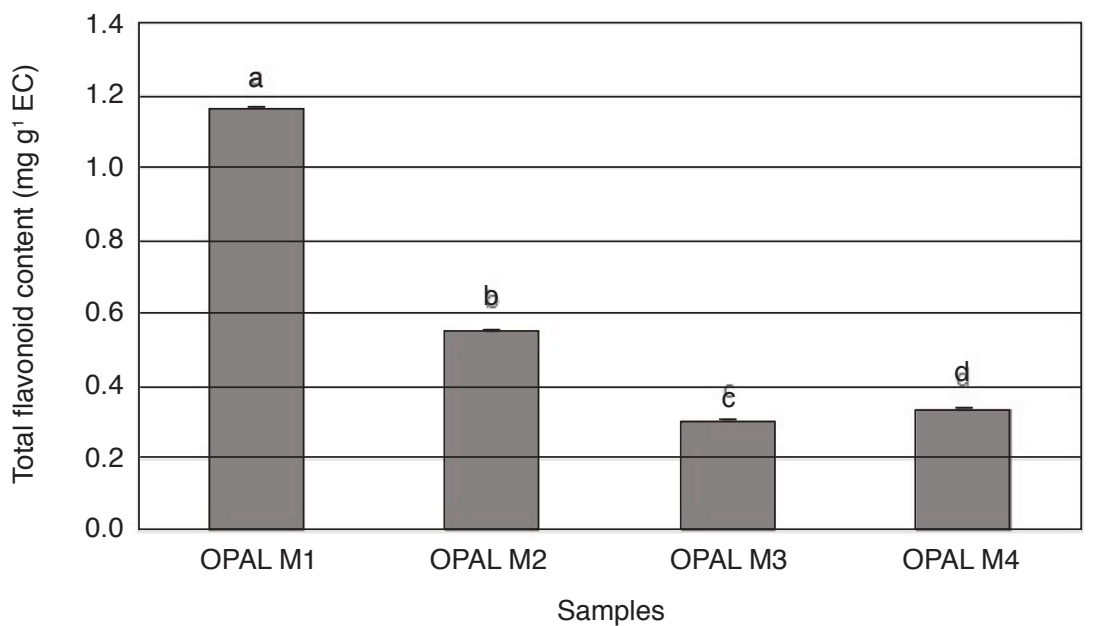

Figure 4. Total flavonoid content (TFC) of oil palm leaves (OPAL) extract from various methods of extraction calculated as mg epicathecin (EC) $g^{-1}$ sample. Values in the same column followed by different letters indicate significant differences $(p<0.05)$. 


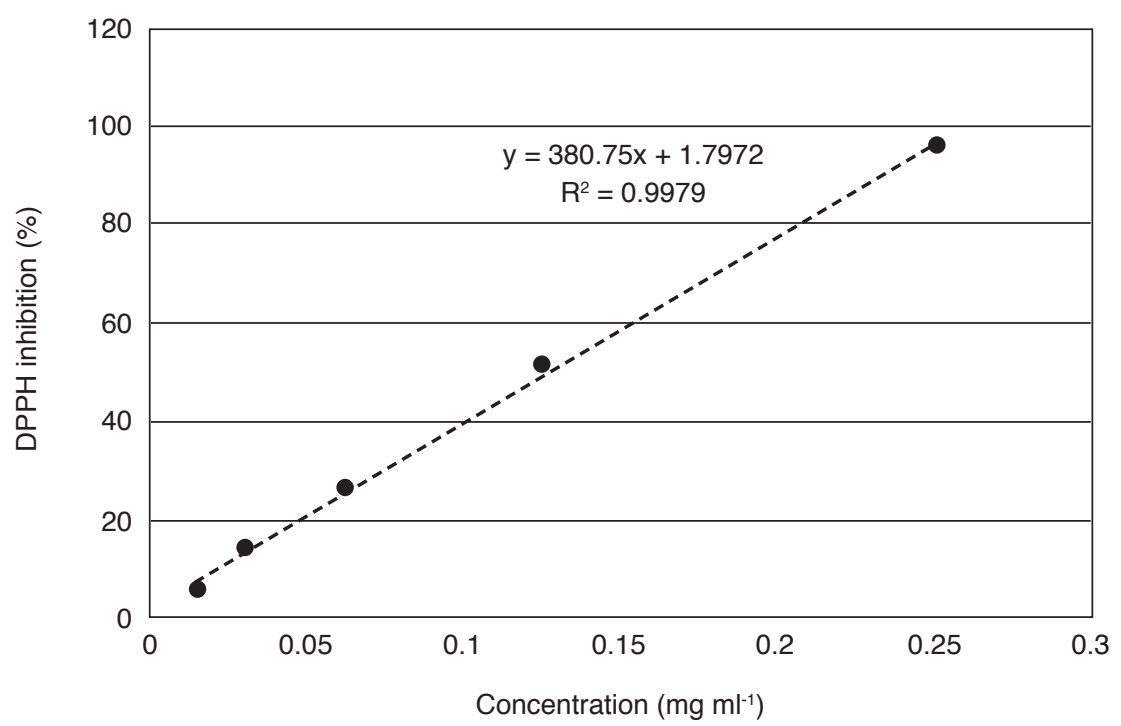

Figure 5. Standard calibration curve of Trolox.

concentrations ranging from 0.015625 to $0.25 \mathrm{mg}$ $\mathrm{ml}^{-1}$ in methanol. Alam et al. (2013) reported that DPPH is widely used as a substrate to evaluate antioxidative activity of antioxidants. The advantages of using DPPH method are fast, easy and reliable. In addition, the method does not require a special reaction and device. Besides, it is a stable radical and does not disintegrate in water, methanol and ethanol (Aksoy et al., 2013). A DPPH radical react with antioxidants in the sample solution and is converted into DPPH-H (diphenylhydrazine) as shown in the following equation. The deep purple colour of the DPPH will be decreased due to the decreasing quantity of DPPH radicals in the sample studied and it can be detected spectrophotometrically at 515 nm.

\section{$\mathrm{DPPH}^{\bullet}+\mathrm{A}-\mathrm{H}$ DPPH-H $+\mathrm{A}^{\bullet}$}

The OPAL extracts and BHT showed a concentration-dependent anti-radical activity (Figure 6). The total antioxidant activity of OPAL extracts and BHT were compared with Trolox. At a concentration of $0.25 \mathrm{mg} \mathrm{ml}^{-1}$, the antioxidant activities of the extracts and BHT determined by DPPH assay were ranked as Trolox $>$ BHT $>$ OPAL M1 OPAL M2 OPAL M3 OPAL M4 with percentage DPPH inhibition was 95.78, 78.63, 36.09, 25.32, 18.07 and 15.47 , respectively. ANOVA detected significant difference among the examined samples with $\mathrm{p}<0.05$. Table 1 shows values of $\mathrm{IC}_{50}$ of the OPAL extracts, BHT and Trolox. The values were mean (n $=3) \pm$ SD. Values for all samples were significant different with $\mathrm{p}<0.05$. The low $\mathrm{IC}_{50}$ value indicates higher antioxidant activity. In this study, the OPAL M1 extract showed the lowest $\mathrm{IC}_{50}$ value of $0.461 \mathrm{mg}$ $\mathrm{ml}^{-1}$ compared to other examined extracts except for Trolox and BHT. The $\mathrm{IC}_{50}$ value of OPAL M1 was lower than value reported by $\mathrm{Ng}$ et al. (2013) with $\mathrm{IC}_{50}$ was $0.646 \mathrm{mg} \mathrm{ml}^{-1}$ but higher than value reported by Yusof et al. (2016) with $\mathrm{IC}_{50}$ was 0.247 $\mathrm{mg} \mathrm{ml}^{-1}$. Results of the present study showed that although antioxidant activity of the OPAL extracts is less effective than BHT, but they can be added at higher amounts in order to have similar antioxidant activity.

Many literatures have reported a positive correlation between antioxidant activity and TPC (Faujan et al., 2009; Li et al., 2009; Sun and Ho, 2005). In this study, a positive correlation was observed for OPAL extracts where increasing amount of TPC resulted in higher antioxidant activity for all OPAL extract samples.

\section{Effect of OPAL Extracts and BHT on Transparency and Colour Luminosity of Transparent Soap}

Soap is available in three characteristics i.e. opaque, translucent and transparent. Transparent soap is more attractive to consumers and requires a high quality of materials to be incorporated compared to opaque and translucent soap. According to Dumas and Helmond (1995), the transparent soap must be transparent enough which has the ability to read a bold word with 14 font size through a 0.25 inch or $6.4 \mathrm{~mm}$ soap thickness. Figure 7 shows the transparency and colour of transparent soap at $0.1 \%$ and $0.5 \%$ of OPAL extracts and BHT. The addition of $0.1 \%$ extract resulted in acceptable soap transparencies for all samples as the bolded word can clearly be seen through the $6.4 \mathrm{~mm}$ soap thickness. However, the addition of $0.5 \%$ extract resulted in completely dark soaps for OPAL M1 and OPAL M3 extracts while OPAL M2 and OPAL 


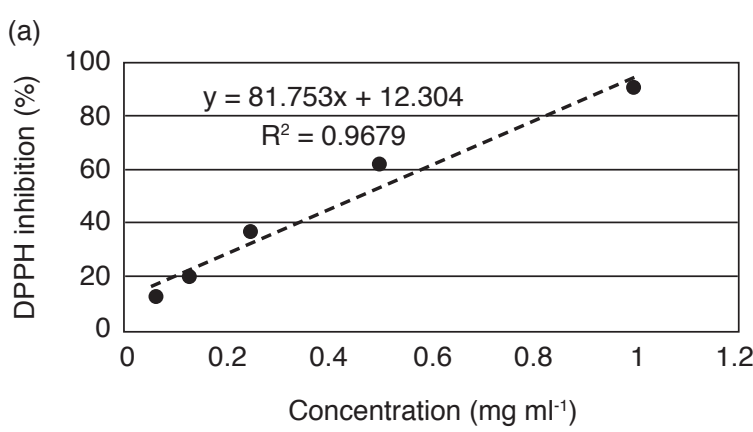

(c)

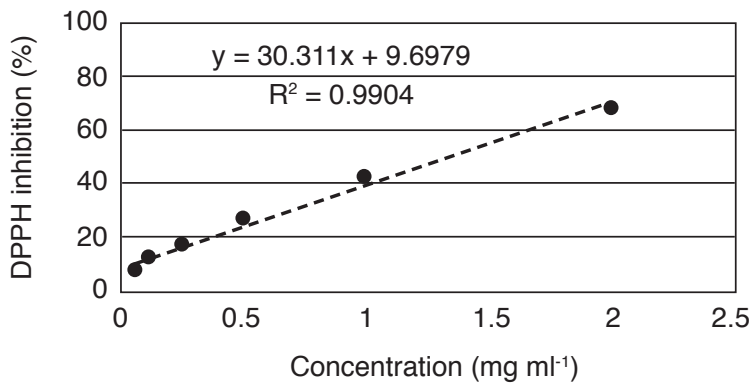

(b)

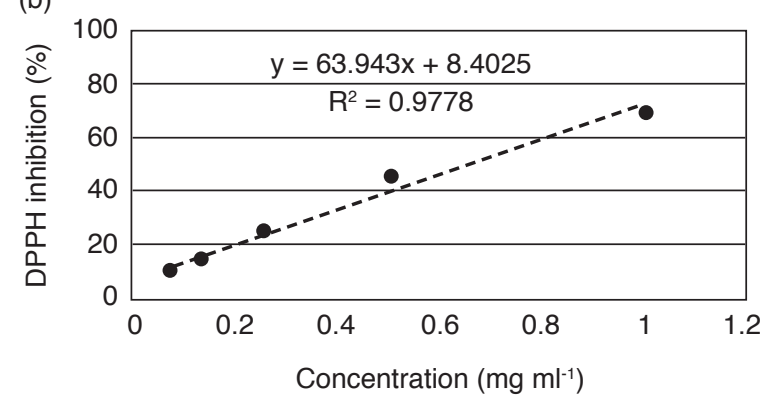

(d)

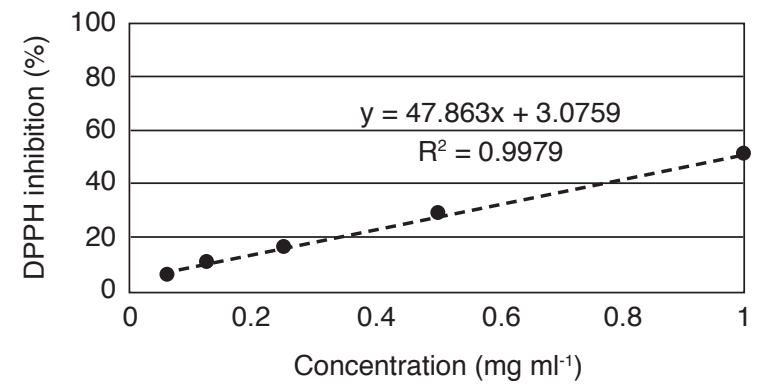

(e)

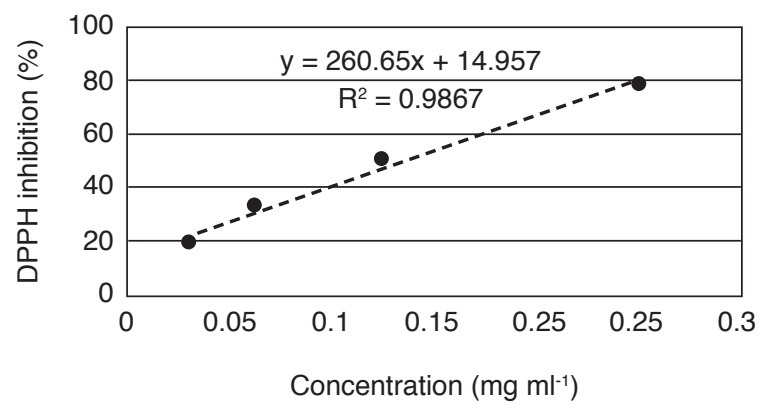

Figure 6. Effect of different concentrations of extracts a) OPAL M1, b) OPAL M2, c) OPAL M3, d) OPAL M4 and e) butylated hydroxytoluene (BHT) on diphenyl-1-picrylhydraszl (DPPH) inhibition.

TABLE 1. THE VALUES OF IC $_{50}$ OF TROLOX, OPAL AND BHT IN DECREASING ORDER OF ANTIOXIDANT ACTIVITY

\begin{tabular}{cc}
\hline Sample $(\mathbf{n}=3)$ & $\mathbf{I C}_{50}\left(\mathrm{mg} \mathrm{ml}^{-1}\right)$ \\
\hline Trolox & $0.127 \pm 0.000$ \\
BHT & $0.134 \pm 0.000$ \\
OPAL M1 & $0.461 \pm 0.004$ \\
OPAL M2 & $0.651 \pm 0.005$ \\
OPAL M4 & $1.036 \pm 0.001$ \\
OPAL M3 & $1.330 \pm 0.010$ \\
\hline
\end{tabular}

Note: OPAL - oil palm leaves.

BHT - butylated hydroxytoluene.

M4 gave relatively acceptable soap transparencies. Besides, the colours for all soaps were also changed with the addition of all extracts. The colour intensity observation was supported by data obtained from chroma meter lightness $\left(\mathrm{L}^{*}\right)$ scale results as illustrated in Figure 8. By incorporating the extract, the colour of transparent soaps were significantly different than the control sample and became less bright with an increasing amount of extract. It was observed that the brightness of transparent soap also decreased with increasing flavonoid and phenolic content. The benchmark, soap with 0.1 and $0.5 \%$ BHT provided a hazy appearance which slightly affect the transparency of the soap. The order of soaps at $0.1 \%$ active in increasing brightness was as follows: transparent soap with OPAL M1 $<$ transparent soap with OPAL M3 < transparent soap with OPAL M2 $<$ transparent soap with OPAL M4 < transparent soap with BHT < control. It was also found that OPAL M3 extract was difficult to dissolve in the soap base. This observation may be due to the insoluble extract in the soap which affects the brightness measurements. 


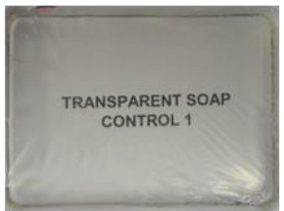

Control (placebo)

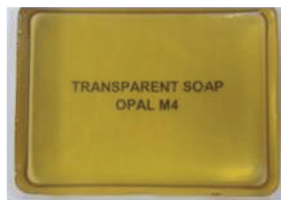

OPAL M4 (0.1\%)

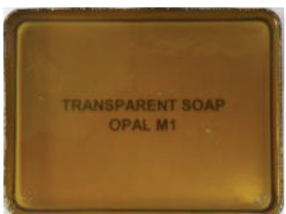

OPAL M1 (0.1\%)

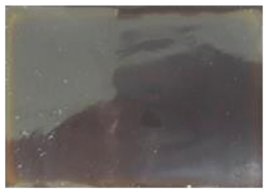

OPAL M1 (0.5\%)

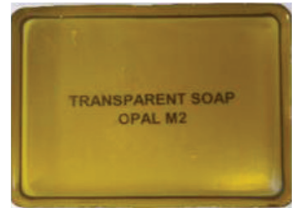

OPAL M2 (0.1\%)

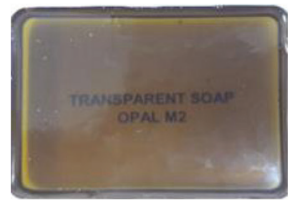

OPAL M2 $(0.5 \%)$

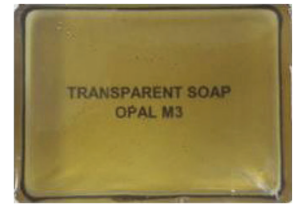

OPAL M3 (0.1\%)

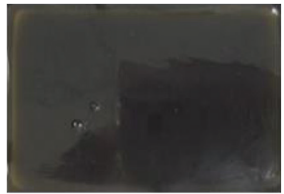

OPAL M3 $(0.5 \%)$

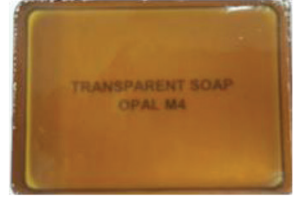

OPAL M4 (0.5\%)

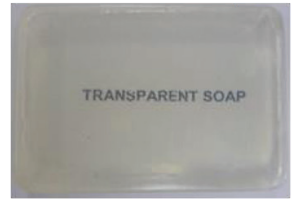

$\mathrm{BHT}(0.1 \%)$

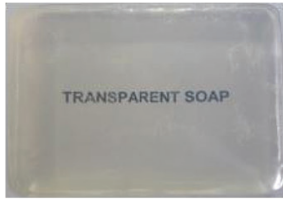

$\mathrm{BHT}(0.5 \%)$

Figure 7. Transparency and colour of palm-based transparent soap with $0.1 \%$ and $0.5 \%$ of oil palm leaves (OPAL) extracts and butylated hydroxytoluene (BHT).

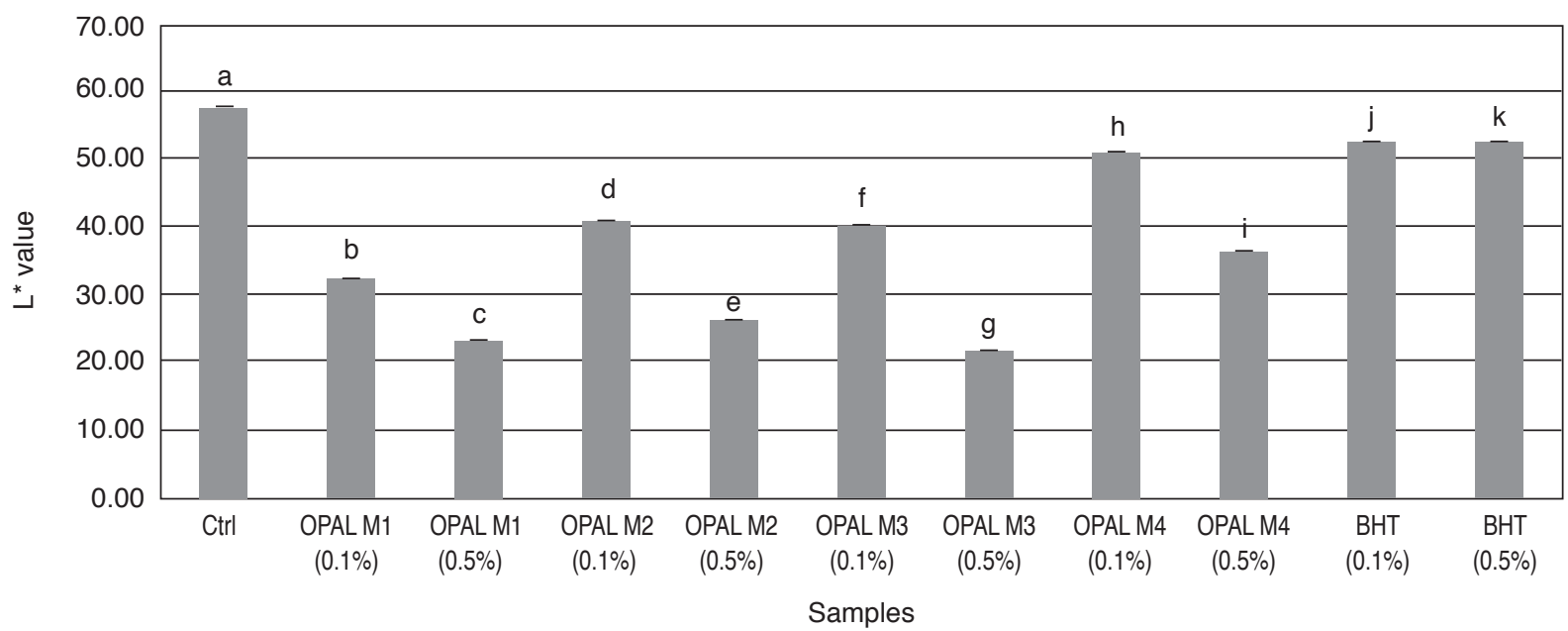

Note: Ctrl - control sample. Values in the same column followed by different letters indicate significant differences $(p<0.05)$. Lower $\mathrm{L}^{*}$ value indicates dark colour of the soap.

Figure 8. Luminosity of palm-based transparent soap with $0.1 \%$ and $0.5 \%$ of oil palm leaves (OPAL) extracts and butylated hydroxytoluene (BHT).

\section{CONCLUSION}

OPAL M1 and OPAL M2 extracted with ethanol contain the highest amount of phenolics and flavonoids compared to OPAL M4 extracted in aqueous because phenolics and flavonoids are very soluble in ethanol. However, OPAL M3 extracted by ethanolic $\mathrm{HCl}$ showed the lowest phenolics and flavonoids content due to the acidification process that reduces the stability of the compounds.
Moreover by removing the waxy materials, the OPAL M2 extract was easier to be dissolved and incorporated in the product formulation. All OPAL extracts gave similar antioxidant activities to BHT but required higher concentration. Thus, OPAL extracts can be used as natural antioxidant. The advantages of adding OPAL extract in transparent soap formulations are it provides natural a yellow colour, good antioxidant activity and transparency at $0.1 \%$ of extract. 


\section{ACKNOWLEDGEMENT}

The authors are thankful to the Director-General of MPOB for permission the to publish this article. Special thanks to Nurul Ain Mohd Arzani (Consumer Product Development Unit, Advanced Oleochemical Technology Division), Mohd Nor Mamat@ Jusoh (Consumer Product Development Unit, Advanced Oleochemical Technology Division) and Zulkiffli Razali (Analytical and Quality Development Unit, Product Development Research and Advisory Services Division) for their assistance.

\section{REFERENCES}

ABDELHADY, M I S; MOTAAL, A A and BEERHUES, L (2011). Total phenolic content and antioxidant activity of standardized extracts from leaves and cell cultures of three Callistemon species. Am. J. Plant Sci., 2: 847-850. DOI: 10.4236/ ajps.2011.26100.

AKSOY, L; KOLAY, E; AĞILÖNÜ, Y; ASLAN, Z and KARGIOĞLU M (2013). Free radical scavenging activity, total phenolic content, total antioxidant status, and total oxidant status of endemic Thermopsis turcica. Saudi J. Biol. Sci., 20(3): 235-239. DOI: 10.1016/j.sjbs.2013.02.003.

ALAM, M N; BRISTI, N J and RAFIQUZZAMAN, M (2013). Review on in vivo and in vitro methods evaluation of antioxidant activity. Saudi Pharm. J., 21(2): 143-152.

ALOTHMAN, M; BHAT, R and KARIM, A A (2009). Antioxidant capacity and phenolic content of selected tropical fruits from Malaysia, extracted with different solvents. Food Chem., 115: 785-788.

DAVIDOV-PARDO, G; AROZARENA, I and MARÍN-ARROYO, M R (2011). Stability of polyphenolic extracts from grape seeds after thermal treatments. Eur. Food Res. Technol., 232: 211-220.

DO, Q D; ANGKAWIJAYA, A E; TRAN-NGUYEN, P; HUYNH, LH; SOETAREDJO, F E; ISMADJI, S and JU, Y (2014). Effect of extraction solvent on total phenol content, total flavonoid content, and antioxidant activity of Limnophila aromatica. J. Food Drug Anal., 22(3): 296-302.

DUMAS, E J P and HELMOND, J (1995). Process for making transparent soaps. European patent EP 0710276 A1, accessed on 2 February 1995.

ENUJIUGHA, V N; TALABI, J Y; MALOMO, S A and OLAGUNJU, A I (2012). DPPH radical scavenging capacity of phenolic extracts from African yam bean
(Sphenostylis stenocarpa). Food and Nutr. Sci., 3: 7-13. DOI:10.4236/fns.2012.31002.

FAUJAN, N H; NORIHAM, A; NORRAKIAH, A S and BABJI, A S (2009). Antioxidant activity of plants methanolic extracts containing phenolic compounds. Afr. J. Biotechnol., 8(3): 484-489.

FEILD, T S; LEE, D $\mathrm{W}$ and HOLBROOK, N M (2001). Why leaves turn red in autumn: The role of anthocyanins in senescing leaves of red-osier dogwood. Plant Physiol., 127: 566- 574.

HALLIWELL, B (1996). Antioxidants in human health and disease. Annu. Rev. Nutr., 16: 33-50.

INSTONE, T and BOTTARELLI, M (1991). Transparent soap bars which may contain short chain monohydric alcohols, and a method of making the same. US patent $5,041,234 \mathrm{~A}$, issued date 20 August 1991.

JAFFRI, J M; MOHAMED, S; ROHIMI N; AHMAD, I N; NOORDIN, M M and MANAP, Y A (2011). Antihypertensive and cardiovascular effects of catechin-rich oil palm (Elaeis guineensis) leaf extract in nitric oxide-deficient rats. J. Med. Food., 14 (7/8): 775-783. DOI: $10.1089 /$ jmf.2010.1170.

KHODDAMI, A; MEREDITH, A W and THOMAS, H R (2013). Techniques for analysis of plant phenolic compounds. Molecules, 18: 2328-2375. DOI: 10.3390/ molecules18022328.

LI, X; WU, X and HUANG, L (2009). Correlation between antioxidant activities and phenolic contents of radix angelicae sinensis (Danggui). Molecules, 14: 5349 - 5361. DOI: 10.3390/molecules14125349.

MORTENSEN, A (2006). Carotenoids and other pigments as natural colourants. Pure Appl. Chem., 78(8): 1477 -1491.

NEO, Y P; ARIFFIN A; TAN, C P and TAN, Y A (2008). Determination of oil palm fruit phenolic compounds and their antioxidant activities using spectrophotometric methods. Int. J. Food Sci. Technol., 43: 1832-1837. DOI: 10.1111/j.13652621.2008.01717.x.

NG, M H and CHOO, Y M (2010). Determination of antioxidants in oil palm leaves (Elaeis guineensis). Am. J. Appl. Sci., 7(9): 1243-1247.

NG, S Y; ABDULLAH, S and CHONG, K P (2013). Phytochemical constituents from leaves of Elaeis guineensis and their antioxidant and antimicrobial activities. Int. J. Pharm. Pharm. Sci., 5(4): 137-140. 
RUNNIE, I; MOHAMED MUSTAPHA, N; MUSEC, R; HAMID, A; NAWAWID, H; ABEYWARDENAE, M Y and MOHAMED, S (2003). Antioxidant and hypocholesterolemic effects of Elaeis guineensis frond extract on hypercholesterolemic rabbits. ASEAN Food J., 12(3): 137-148.

SHAHIDI, F and YEO, J (2016). Insoluble-bound phenolics in food - A review. Molecules, 21(9): 1-22. DOI: 10.3390 / molecules21091216.

SINGLETON, V L and ROSSI, J A (1965). Colourimetry of total phenolics with phosphomoblydic-phosphotungstic acid reagents. Am. J. Enol. Vitic., 16: 144-158.

SUHAILA, M (2014). Oil palm leaf: A new functional food ingredient for health and disease prevention. J. Food Process. Technol., 5(2): 1-6.

SUN, T and HO, C T (2005). Antioxidant activities of buckwheat extracts. Food Chem., 90: 743-749.

SUN, B and FUKUHARA, M (1997). Effect of co-administration of butylated hydroxytoluene, butylated hydroxyanisole and flavonoids on the activation of mutagens and drug metabolizing enzymes in mice. Toxicology, 122: 61-72.

TASIOULA-MARGARI, $M$ and TSABOLATIDOU, E (2015). Extraction, separation and identification of phenolic compounds in virgin olive oil by
HPLC-DAD and HPLC-MS. Antioxidants, 4: 548562.

THAIPONG, K; BOONPRAKOB, U; CROSBY, K; CISNEROS-ZEVALLOS, L and BYRNE, D H (2006). Comparison of ABTS, DPPH, FRAP and ORAC assays for estimating antioxidant activity from guava fruit extracts. J. Food Comp. Anal., 19: 669 675. DOI: $10.1016 /$ j.jfca.2006.01.003.

WATERHOUSE, A L (2002). Polyphenolics: Determination of total phenolics. Current Protocols in Food Analytical Chemistry (Wrolstad, R E ed.). John Wiley and Sons, Inc., New York. p.1-4.

YAMAKI, K; TANEDA, $S$; YANAGISAWA, R; INOUE, K; TAKANO, H and YOSHINO, S (2007). Enhancement of allergic responses in vivo and in vitro by butylated hydroxytoluene. Toxicol. Appl. Pharmacol., 223: 164-172.

YEN, G C and DUH, P D (1994). Scavenging effect of methanolic extracts of peanut hulls on free-radical and active-oxygen species. J. Agric. Food Chem., 42(3): 629 - 632. DOI: 10.1021/jf00039a005.

YUSOF, N Z; ABD GANI, S S; SIDDIQUI, Y; MOHD MOKHTAR, N F and AZIZUL HASAN, Z A (2016). Potential uses of oil palm (Elaeis guineensis) leaf extract in topical application. J. Oil Palm Res. Vol. 28(4): 520-530. 